\title{
ENSINO DE 20 GRAU: EM BUSCA DE UMA ORGANIZAÇÃO CONDIZENTE COM AS NOVAS DETERMINAÇÕES POSTAS PELO MERCADO DE TRABALHO
}

\author{
Maria Beatriz Loureiro de Oliveira*
}

\section{RESUMO}

Com o objetivo de compreender o papel e a função fundamental da educação em nível de $2^{\mathfrak{Q}}$ grau, este artigo tem o intuito de proporcionar ao leitor uma visão dos avanços e possíveis retrocessos acerca do assunto, na discussão que se trava nos meios acadêmicos, buscando fazer uma síntese das idéias correntes sobre o ensino de $2^{2}$ grau.

\section{INTRODUÇÃO}

As reformas do ensino são a expressão das tentativas empreendidas no sentido de ajustar a estrutura escolar a cada uma das etapas de desenvolvimento do processo produtivo, procedimento este que vem acoplado às políticas públicas adotadas pelo Estado, quase sempre em benefício de determinados setores da sociedade civil, sem no entanto se obterem os efeitos desejados.

Entretanto, a intervenção do Estado na organização escolar, através da elaboração da legislação pertinente, via de regra esbarra na forma como vem evoluindo a sociedade brasileira.

Em análise crítica à legislação escolar, Saviani observa que: "a organização escolar não é obra da legislação. Ambas interagem no seio da sociedade que produz uma e outra. $O$ exame do contexto nos permite inferir, por

\footnotetext{
* Professora Assistente Doutor junto ao Departamento de Psicologia da Educação da Faculdade de Ciências e Letras da UNESP - Campus de Araraquara.
} 
exemplo, que a expansão quantitativa do ensino brasileiro após 1964, com todas as conseqüências daí advindas, teria ocorrido com ou sem a reforma da legislação; seu fator determinante está na forma como vinha evoluindo a sociedade brasileira. A legislação constitui o instrumento através do qual o Estado regula, acentuando ou amenizando as tendências em marcha" (Saviani, 1976, p. 193).

Indicando a necessidade de se fazer uma análise crítica da legislação do ensino, Saviani propõe que se ultrapasse o texto da lei e se examine o contexto; a fim de captar os determinantes. As proclamações existentes nos textos legais exprimem as contradições entre as condições objetivas da sociedade, evidenciadas pela ruptura política da Revolução de 1964, e aquelas manifestas no seio da organização escolar. Não se pode esperar que a lei opere mudanças profundas quando estas não se processaram em nível da sociedade.

Os estudiosos do ensino em nível de $2^{2}$ grau citados neste artigo, tentam apreenderas contradições entre o real e o desejável a partir das condições objetivas da sociedade.

\section{EDUCAÇÃO E TRABALHO; UMA SINTESE DAS IDÉIAS CORRENTES SOBRE O TEMA A PARTIR DA DECADA DE 80.}

Entendendo a questão da inovação tecnológica como um dos fatores determinantes dos novos rumos da educação e do ensino a nível de $2^{2}$ grau, nossa preocupação neste momento é a de retomar as discussōes já num estágio mais avançado para que se vislumbre uma proposta educacional condizente com as novas determinações postas pela modernidade.

Kuenzer (1988), ao se propor captar o movimento das idéias em sua relação com as peculiaridades do desenvolvimento brasileiro mais recente, parte das abordagens que tiveram caráter dominante no Brasil, especialmente a partir da década de 60 , época em que há um desenvolvimento mais sistemático da pesquisa em educação no país. Neste momento difunde-se no Brasil a Teoria do Capital Humano. A autora refere-se à entrada, ao fortalecimento e ao significado desta teoria que, do ponto de vista metodológico, está embasada em uma concepção positivista de educação e tem o empirismo como método. 
Destaca que esta corrente, de origem norte-americana, se constitui num dos suportes ideológicos do regime instaurado a partir de 1964 enquanto respalda o modelo desenvolvimento com segurança, resultado da aliança entre Forças Armadas, capitalismo internacional e capitalismo nacional.

A palavra de ordem passou a ser a racionalização tanto do sistema produtivo como de todos os setores da vida social através do desenvolvimento tecnológico e da administração científica.

Os riscos de desestabilização social originários do modelo econômico adotado evidenciavam a necessidade de uma ideologia que sustentasse a meta do crescimento econômico como forma de superação das medidas centralizadoras e restritivas à participação da sociedade civil, advindas dos novos mecanismos de poder exercido pelo Estado e do crescente controle financeiro tecnologico exercido pelo capital internacional.

Esta ideologia aponta como solução a qualificação profissional dos indivíduos que, ancorada na "Teoria do Capital Humano", supunha o aumento da produtividade marginal e a conseqüente elevação dos salários. (Kuenzer, 1988, p. 42)

O aumento da produtividade via racionalização foi transposto para o sistema de ensino, e a educação concebida como instrumento eficaz de promover o desenvolvimento econômico via qualificação do trabalhador.

Warde (1985) admite que até a década de 70 houve o predomínio das pesquisas com forte teor doutrinário de referência liberal e empiricista, supostamente assimiladas nas próprias Reformas do ensino implantadas em 1968 e especialmente em 1971.

A partir de 1970, predominam os trabalhos na perspectiva chamada de reprodutivismo.

Esta perspectiva de análise teve a intenção explícita de romper com a parâmetro doutrinário liberal e abandonar as bases do empiricismo. Apoiados nos grandes teóricos do estruturalismo estas teorias buscavam rechaçar $o$ empiricismo.

Warde adverte para o fato de que, naquele momento, não se tinha clareza sobre quais eram as bases doutrinárias e os suportes metodológicos utilizados para fazer a crítica ao empiricismo que se estava rejeitando. (Warde, 1985, p. 34-35) 
Já no final de 1970 e início de 1980 o reprodutivismo passou a ser repensado tentando, nesta fase, recuperar o dado empírico cujo objetivo era fazer pesquisa numa perspectiva dialética, onde o elemento empírico e a recuperação do concreto são condições fundamentais (Warde, 1985, p. 35).

Na relação entre pesquisa e política educacional, o que se observa é que a gama de pesquisa sobre o ensino de $2^{\circ}$ Grau respaldou, de fato, o redirecionamento da Lei 5692/71 que se concretizou na Lei 7044/82 em que se restabelece a formação geral básica e se secundariza a formação específica.

E importante salientar que a inquietação, resultante da oscilação acerca do ensino de $2^{2}$ grau, em que ora se rechaça a profissionalização, tida como no mínimo um erro de avaliação, ora se pensa em restabelecê-la, permanece, de certa forma, até os nossos dias.

Umbelina Salgado (1985), a quem se imputa uma grande responsabilidade como uma das mentoras da Lei 7044/82, em debate realizado na Fundação Carlos Chagas em 1984, propõe que se recupere as escolas técnicas que perderam a sua especificidade pela banalização do diploma, pelos desvios de seus objetivos que se tornaram propedêuticas ou pela tentativa de se transformar em cursos de tecnólogos de $3^{\circ}$ grau. (Salgado, 1985, p. 39).

A autora explicita ainda a necessidade de se "revitalizar o ensino técnico" com a ressalva de que se deveria estar atento para os riscos existentes com relação às pesquisas na sua relação com a política educacional, os quais deveriam ser tomados como pontos de referência.

O primeiro risco "é pura e simplesmente a profissionalização na escola, sem levar em conta a situação da cidadania regulada pela efịciência do mercado, sendo pois a qualificação profissional interesse concreto, imediato, dos alunos das classes populares".

O segundo risco, refere-se ao fato de que recuperar os cursos profissionalizantes pode levar a "outras formas de dualidade do sistema de ensino" resultado de políticas equivocadas. $O$ terceiro refere-se à necessidade de se colocar os resultados das pesquisas numa perspectiva mais ampla e contextualizada para que se defina a quem servem; e, por último, em contraposição ao anterior, seria a necessidade de não se adotar um basismo ingênuo, quando se toma como o único "saber legítimo" as demandas feitas pelo trabalhador e desta forma condenálo a permanecer na posição que ocupa. (idem) 
Embora se pontue alguns cuidados no sentido de não haver um retrocesso em matéria de política educacional, de qualquer forma pensa-se em revitalizar o ensino técnico estruturado com base nos conhecimentos da técnica necessária ao exercício da profissão. Atende-se à demanda de mercado, revitalizando o que se considera positivo em matéria de profissionalização, e se pontua alguns cuidados em matéria de política educacional.

Curiosamente não se têm como referência importante o fenômeno da incorporação da ciência como força produtiva na indústria, o que, de certa forma, vem revolucionando os requerimentos da mão-de-obra nesse setor da produção.

$\mathrm{Na}$ definição do tipo de saber a ser proporcionado pela escola deve-se ter como ponto de partida as circunstâncias concretas da produção, tendo em vista o atual patamar de desenvolvimento social geral em que há uma crescente incorporação da ciência e da técnica à produção (1). Na tese citada considero que, tendo em vista o desenvolvimento das forças produtivas, mudam os requerimentos básicos para a formação do trabalhador, no sentido em que esse tipo de desenvolvimento pressupõe a ampliação da gama de conhecimentos necessários para que se possa operar um sistema de máquinas. Portanto, o processo de complexificação da sociedade moderna traz, embutida na sua própria organização, um grau de qualificação mais amplo e, no campo específico da prática educativa escolar, coloca-se a exigência de maior escolarização no sentido de se requerer das pessoas um saber de caráter mais fundamental.

As idéias decorrentes das teorias da "economia da educação" que evidenciam a expropriação absoluta do saber da classe trabalhadora, não consideram o desenvolvimento das forças produtivas como um desenvolvimento social geral. Assim, quanto à educação, consideram que ou o trabalhador se submete à lógica de valorização do capital ou esta se desvincula do mundo do trabalho, tornando-se uma educação geral, de cunho propedêntico, da forma como vem sendo posta pelo sistema de ensino, especialmente em nível de $2^{\circ}$ grau.

Em meu estudo, citado anteriormente, quando trato das teorias sobre a (des) qualificação do trabalhador e a educação, observo que as contradições que se estabelecem entre o avanço das forças produtivas e as relações de produção sob o capitalismo trazem, para o âmbito da educação e do

(1) Ver sobre o assunto OLIVEIRA, Maria Beatriz L. de. 
ensino, a necessidade de se pensar a escola com base na união entre ensino e trabalho produtivo e, neste sentido, verificar, a partir das condiçōes objetivas da produção, a possibilidade de reconquista, ou melhor, de conquista, pela classe trabalhadora, do domínio destas condições.

Frigotto (1984), ao tratar das condições históricas que demandam e produzem a "Teoria do Capital Humano", mostra como a passagem dos modos de produção pré-capitalistas para o dominantemente capitalista se processou. A mudança essencial havida no processo de trabalho é que o trabalho humano serve de mediação entre as máquinas e a natureza. A habilidade do trabalhador deixa de ser um limite para o capital. Inverte-se o primado do trabalho sobre os meios de produção.

Com o avanço da técnica, tendo em vista o processo de incorporação da ciência e da técnica ao capital, o trabalhador fica subsumido aos ditames da nova tecnologia incorporada pelo capital. Esta mudança determina o que Marx denominou de subsunção real do trabalho ao capital em substituição ao processo de subsunção formal do trabalho ao capital, em que o trabalhador dispunha ainda de algum controle sobre o processo de produção.

Portanto, ao evidenciar o "progresso técnico" como elemento chave para entender as novas determinações existentes no modo de produção capitalista, Frigotto acrescenta que "este processo histórico onde o capital, enquanto uma relação social, busca desvencilhar-se cada vez mais da dependência dos limites impostos pelo trabalhador, pela resistência que este lhes impõe, desenha-se como um processo onde se busca expropriar do trabalhador os meios concretos desta resistência - seu saber, sua qualificação, o domínio de técnicas, sua agilidade, etc. A separação entre o operário e o seu instrumento vai determinando uma separação entre trabalhador e conhecimento, entre trabalhador e ciência" (Frigotto, 1984, p. 83)

Fragiliza-se o poder de barganha do trabalhador (o que exige novas formas de organização e de ação da classe trabalhadora), e o capital instaura seu processo pedagógico próprio.

Já no início deste século, Gramsci (1978) ao analisar a decadência e a crise da escola italiana, cujo esquema tido como "racional" dividia a escola em clássica e profissional, propõe um novo tipo de racionalidade e, tendo como parâmetro a experiência adquirida durante sua permanência na União Soviética, indica como solução para tal crise, o politecnicismo, ou seja, a escola única do trabalho. Em suas palavras, "a crise terá uma solução que, racionalmente, deveria 
seguir esta linha: escola única inicial de cultura geral, humanística, formativa, que equilibra equanimemente o desenvolvimento da capacidade de trabalhar manualmente (tecnicamente, industrialmente) e o desenvolvimento das capacidades de trabalho intelectual. Deste tipo de escola única, através de repetidas experiências de orientação profissional, passar-se-á a uma das escolas especializadas ou ao trabalho produtivo" (Gramsci, 1978, p. 118).

Reiteramos as assertivas de Manacorda (1977) quando esclarece que Gramsci tem diante de si, o modelo soviético que havia conhecido na época revolucionária e que o deputado italiano combatia veementemente o giro conservador dado pela pedagogia stalinista, com o intuito de permanecer fiel à hipótese original de Marx e de Lenin: uma escola única ao mesmo tempo de cultura e de trabalho. Gramsci já considera, por volta dos anos 30, o fato da ciência haver se tornado produtiva e da prática haver se complexificado, devido ao desenvolvimento de base industrial tanto na cidade como no campo. Propõe então um modelo cuja perspectiva racional rompe com a velha racionalidade. (Manacorda, 1977, p. 172-173)

Maria Laura Franco (1985), vê o ensino técnico em nível de $2^{2}$ grau como uma das alternativas da educação média. O sistema formal de ensino, especialmente a escola pública, é um compromisso que se deve assumir, preparando o aluno para o mundo do trabalho. Adverte, porém, que isto não deve significar um mero adestramento.

Dever-se-ia priorizar a boa qualidade de ensino e os conteúdos que desmistificam as explicações ideológicas. (Franco, 1985, p. 42)

Nessa postura, o trabalho na escola deve recuperar sua dimensão real e histórica. A luta pela hegemonia da classe proletária ficaria atrelada a um processo de instrumentalização política das massas supondo-se que, munidas do novo aparato político-ideológico, pudessem assim combater as condições de alienação do trabalho humano a que estão submetidas.

É preciso explicitar que, neste momento, já se tem clareza acerca do desenvolvimento do sistema educacional em função dos interesses de um setor específico da sociedade, bem como do papel que desempenham os Centros de Treinamentos, SENAI e similares, o Sistema Nacional de Formação de mão-de-obra, como entidades que devem garantir a especificidade dos postos de trabalho e a coesão da elite intelectual da empresa.

Fica nítido o papel que o Estado desempenha no sentido de oferecer condições para que as empresas oligopólicas, multinacionais, possam se 
instalar. A educação tem grande importância dentre as condiçōes infraestruturais nccessárias à realização deste objetivo.

Outro lado, é que a demanda do mercado pelo ensino de $2^{2}$ grau profissionalizante era de fato autoritária. Já havia um grande questionamento sobre o relacionamento da escola com a dinâmica social e a do mercado de trabalho. A absorção dos elementos advindos da escola de habilitação era questionada pela maneira caótica que estava sendo posta, uma vez que os avanços tecnológicos e a saturação do mercado eram fatores fortemente considerados nos debates que se travavam.

Salm (1985) fala textualmente de sua ojeriza pela expressão "necessidades do mercado de trabalho", justificando que os empresários não têm um perfil da mão-de-obra que vão requerer para daí a três ou quatro anos. Isto porque "a dinâmica tecnológica pouco tem a ver com a mão-de-obra, ou seja, não se faz inovações tecnológicas pensando em mão-de-obra, isso não existe. Então, vamos fugir desse negócio de fazer pesquisas de mercado de trabalho para tomar esse tipo de decisão" (Salm, 1985, p. 46)

Referendando seu pressuposto teórico fundamental sobre a relação escola-trabalho, Salm pergunta: "em que" dependem as grandes empresas da escola? Se a grande empresa, diz Salm, está calcada no avanço da ciência e nas hierarquias de poder, à escola resta dar ao jovem "os princípios da ciência, as leis da mecânica, as leis da física - é isso que vai fazê-lo entender o lado científico da produção em que está metido. E ensiná-lo também a lidar com o mecanismo de poder, porque é com isso que ele vai se confrontar no seu dia-a-dia" (idem, p. 45).

Isto o leva a eliminar a possibilidade de se ensinar uma habilitação específica. Entretanto, pelo fato do Brasil ser um país tecnologicamente atrasado, considera que as pequenas e médias empresas que atuam no país dependem do técnico.

Esta afirmação acerca da demanda efetiva das pequenas e médias empresas é contestada por Warde: "ela também dispensa. E dispensa porque esse indivíduo é um pouco mais caro para ela, ele é um pouco mais incômodo para ela e, contraditoriamente, ele vem com algumas sofisticaçōes que ela não tem condições de absorver" (Warde, 1985, p. 48)

Considerando as novas bases postas pelo desenvolvimento das forças produtivas na sociedade contemporânea, que se manifestam pela incorporação crescente da ciência e da tecnologia ao processo de trabalho, 
aponto para uma possível transformação radical do trabalho e do processo de produção posta pela revolução tecnológica que pressupõe, a nível da formação profissional do trabalhador, um novo paradigma. Analiso o tipo de qualificação requerida em função do grau de incorporação da ciência e da tecnologia existente na indústria moderna (Oliveira, 1991).

Considero que, embora este tipo de discussão extrapole ao âmbito deste artigo, serve como parâmetro para análise dos requerimentos de qualificação exigidos pelas pequenas, médias e grandes empresas. Os posicionamentos anteriores, partem dos debates havidos em 1984(2) e de outras produções teóricas deste mesmo ano. Punham em relevo a insuficiência da profissionalização bem como já suscitavam críticas à legislação que se sucedeu à Reforma imposta pela Lei 5692/71, retirando-lhe o caráter de profissionalização.

Madeira (1984) adverte para a necessidade de estudos empíricos que fossem capazes de explicar e explicitar melhor as reais relações entre educação e trabalho no contexto específico da realidade nacional.

Velloso (1984) afirma que as Reformas (tanto no que se refere à 5692/71 quanto à 7044/82) destinam-se a amortecer as contradiçōes entre o papel da escola e sua correspondência com as necessidades do modo de produção capitalista.

Constatamos que grande parte dos estudiosos do assunto durante este período, preocupavam-se com o suposto papel socializador da escola que não se concretizou, indicando como fatores relevantes seja a função contendora do ensino de $2^{\circ}$ grau profissionalizante, que provocaria uma inflexão na curva de crescimento da educação de nível superior, seja a dificuldade de acesso e real aquisição do legado cultural existente que a maioria da população jovem encontrava.

A tônica destes discursos era baseada na busca de alternativas mais adequadas e realistas no sentido da melhoria da qualidade técnica do ensino de $2^{0}$ grau, bem como a transformação desse nível de ensino para que o aluno pudesse desenvolver-se enquanto ser histórico e compreender o mundo do trabalho de maneira científica e competente.(3)

2) Estas discussões fizeram parte do Seminário Comemorativo do $20^{\circ}$ aniversário da Fundação Carlos Chagas em novembro do ano de 1984.

(3) Ver Franco, Maria Laura P.B. O Ensino de $2^{\circ}$ Grau: Democratização? Profissionalização? Ou nem uma coisa nem outra? In EM ABERTO, ano 3, n² 19, mar/1984. 
As críticas aos enfoques puramente economicistas da educação formal em nível de $2^{2}$ grau, ou seja, àqueles que se apóiam na "Teoria do Capital Humano", passam a ser feitas a partir de dois veios de análise: um deles, feito a partir do que suscita a Lei 7044/82, que reformula este grau de ensino evidenciando posições em defesa de um ensino generalista e propedêutico e, aparentemente, recusando a submissão da educação às necessidades da produção passa a questionar esta posição e compreende a escola como instância político-ideológica (e que portanto não se caracteriza como instância autônoma), expressão dos momentos de realização e expressão de relações sociais concretas e contraditórias. $O$ outro agrega os que partiam da desvinculação imediata entre escola e trabalho cuja reflexão específica é dirigida para a pedagogia do trabalho. Neste último caso, desloca-se a análise para a escola, cuja pedagogia está voltada diretamente para o trabalho, a chamada pedagogia capitalista, já que consideravam que aí estariam as manifestações mais concretas de exploração, dominação e contradição da sociedade capitalista. (Madeira, 1984, p. 2)

Madeira manifesta sua preocupação com relação ao marco teórico que orienta esta linha de análise, temendo que este encaminhamento acabe por dissolver ainda mais a especificidade da prática educativa e torne mais imprecisos os já confusos limites das relações entre política e educação. Numa breve referência à configuração das relações entre educação e política feita por Saviani, Madeira levanta o risco de se identificar a prática política com a prática pedagógica e em conseqüência dissolver-se ainda mais a especificidade do fenômeno educativo.

Como é notório, Saviani postula a não identidade entre política e educação, os considera fenômenos distintos entre si mas, porém, inseparáveis. Aborda a dimensão política da prática educativa e da dimensão educativa da prática política. A primeira dimensão se explicita a partir da especificidade da prática educativa e a segunda se explicita a partir da especificidade da prática política. Adjetivando a efetiva distinção entre educação e política, aborda a especificidade de cada uma dessas práticas e conclui pela necessidade de se levar em conta "a autonomia relativa da educação em face da política como condição mesma da realização de sua contribuição política". Evidencia que, se a educação for dissolvida na política, desaparecerá a educação e com ela sua função política. (Saviani, 1986, p. 92-94)

Convém observar que uma das correntes explicitadas, resultante das críticas à Teoria do Capital Humano denuncia o caráter potencializador da força de trabalho realizado pelo processo-de escolarização do trabalhador, em que a capacitação, via escola, se subordinava à lógica do capital que se utilizava da 
educação como mecanismo de produção de mais valia e, conseqũentemente, o processo educativo escolar reforçava as relações de exploração existentes na sociedade.

A escola era vista como reprodutora da ideologia burguesa em detrimento dos interesses das classes trabalhadoras e de outras camadas da sociedade. Dissolve-se a educação na política, sem se levar em conta a dimensão política da prática educativa. Por outro lado, as teses da desvinculação imediata entre escola e trabalho postulam a idéia de que o processo escolar não visa atender às demandas específicas do mercado, considerando, portanto, que o mercado funciona autonomamente. Estas concepções, de tendências polarizadas, foram contestadas a partir de seus próprios limites metodológicos. (Oliveira, 1991)

Já incorporadas estas questōes aos discursos dos teóricos da relação educação e trabalho, ao fazerem a crítica aos marcos teóricos das produçōes existentes no âmbito acadêmico, vão, desta forma, perseguindo alternativas mais consentâneas para o problema. A controvérsia sobre a profissionalizaçāo entretanto está longe de ser superada.

Salgado (1985), ao fazer uma análise restrita às contribuições trazidas pelo "Simpósio entre Educação e Trabalho do Jovem" (4), muito embora leve em conta o artigo de Machado (1985) denominado "Cidadania e Trabalho no Ensino de $2^{\circ}$ Grau", como um avanço na definição de uma escola de $2^{2}$ grau - em que a autora mostra estarem superadas, em sua forma tradicional, tanto a escola propedêutica como a profissional, tendo em vista o estágio de desenvolvimento das forças produtivas -, acredita que organizar o sistema educacional de modo a atender a toda a população "não significa acabar com as escolas técnicas e as escolas normais. No caso do ensino técnico, é relevante, inclusive, considerar a questão do mercado, embora não como determinação única ou mais importante para a criação de um curso ou habilitação. Mais do que do comportamento do mercado, a revitalização e o desenvolvimento das escolas técnicas e normais depende de um posicionamento político prévio. Cumpre definir suas especificidades e oferecê-las na medida das demandas da população e de prioridades educacionais democraticamente definidas, tendo em vista as necessidades locais e nacionais" (Salgado, 1985, p. 10).

Considera a autora que o cidadão heje necessita compreender a ciência e a tecnologia que se transformaram nos principais determinantes de

(4) Este Simpósio foi realizado em setembro de 1984 com o apoio do Ministério da Educação, Previdência Social e do Trabalho. 
subsunção real do trabalho ao capital. Já se tem claro o processo de expropriação do "saber" do trabalhador, pretende-se ultrapassar a simples determinação do mercado de trabalho para se pensar a formação do trabalhador. Coloca-se ênfase no posicionamento político prévio visando a elaboração de propostas educacionais demandadas pela população, incluindo-se aí, como uma das variantes, as necessidades locais e nacionais.

Para que se possa esclarecer melhor esse tipo de posicionamento, Salgado (1985) adverte para a necessidade de se adequar o sistema educacional a uma economia industrial moderna, cujos esforços devem se voltar para a recuperação de sua função política. Essa função inclui a formação profissional, porém concebida do ponto de vista do simples atendimento a demandas do mercado de trabalho.

O compromisso com toda a sociedade civil, que deve sobrepor-se ao atendimento a um setor específico da mesma, baliza o tipo de função que o sistema de ensino deve recuperar. Dá-se ênfase a democratização do acesso ao ensino de $2^{\circ}$ grau e à melhoria da qualidade de ensino. A profissionalização não é contestada no seu mérito. A crítica que a ela se faz é no sentido da má articulaçāo dos conteúdos e da falta de recursos humanos, materiais e didáticos para sua concretização.

Machado (1985) já aponta, naquele momento, o caminho para a superação do dilema. A autora afirma que o anacronismo manifesto pelo sistema dual de educação, em que se tem uma escola clássica destinada às classes sociais minoritárias da sociedade versus uma escola profissional que pretende "instrumentalizar os trabalhadores para as atividades produtivas", decorre, fundamentalmente, do avanço do desenvolvimento das forças produtivas que não só exige um aprimoramento técnico das atividades práticas como uma maior articulação entre os problemas gerados pela vida social e o desenvolvimento das ciências.

Neste sentido, considera desatualizados tanto um como outro tipo de escola, cuja situação exige que se faça "uma intervenção consciente e ativa das forças sociais e democráticas no processo de diferenciação que tem se verificado no ensino de $2^{2}$ grau", para que se altere a tradicional dicotomia. (Machado, 1985, p. 35)

Acrescenta-se que se deve superar a defasagem entre o sistema de ensino e as necessidades colocadás pelas condições objetivas existentes numa 
organização social como a nossa, considerando-se o modo como o país participa da divisāo internacional do trabalho.

A importante contribuição que a escola de $2^{\circ}$ grau pode dar, visando o desenvolvimento necessário para que o país alcance o padrão de progresso já posto pelo avanço das forças produtivas, a nível mundial, significa alcançar a própria liberdade.

Diz a autora: "Democratizar o ensino de $2^{\circ}$ grau significa, também, possibilitar ao aluno a posse de capacidades organizativas e diretivas, além daquelas específicas da atividade cognitiva e, para tanto, é preciso que floresçam condições ao exercício da liberdade e da iniciativa". (idem, p. 38)

Concebe-se a escola de $2^{\circ}$ grau como elemento de realização das necessidades que estão postas pela organização social, com vistas à transformação social da sociedade brasileira.

O debate em torno do ensino de $2^{2}$ grau avança para a contextualização desse grau de ensino no bojo da sociedade brasileira, nas suas múltiplas relações.

Nesse cenário, surge o trabalho elaborado por Kuenzer (1985), de grande relevância para a compreensão de que maneira a empresa capitalista educa o trabalhador. A partir de um estudo feito no âmbito da própria fábrica, organizada nos moldes capitalistas, a autora examina como se processam as relaçōes trabalho/educação, ancorada no pressuposto de Marx e Engels de que "o homem se educa, se faz homem, na produção e nas relações de produção" (KUENZER, 1985, p.?).

A partir do cotidiano de uma unidade produtiva e nas relações de produção, Kuenzer tenta compreender o projeto pedagógico que se desenvolve e, de maneira silenciosa e de forma pouco explícita, forma milhares de trabalhadores. Partindo de questões básicas como: que trabalhador é esse, como está sendo educado, por quem e para que, vai buscar respostas a partir de formas características de divisão, organização e heterogestão do trabalho, existentes no interior da produção. Os requisitos de qualificação e de comportamento do trabalhador são determinados a partir de forma de organização do trabalho dividido. A autora examina o processo de hierarquização do trabalhador coletivo e suas implicaçōes sobre a educação do trabalhador que reproduzem as relações de poder do capital sobre o trabalho. 
A importância deste trabalho, ao traçar o perfil do processo educativo existente na fábrica, é a constatação de que a educação do cidadão obedece aos limites impostos pelo capitalismo, o que evidencia o caráter conservador de tal pedagogia. Quanto ao papel da escola, Kuenzer destaca que, historicamente, esta sempre privilegiou a dimensão técnica em detrimento da formação do cidadão que trabalha, obedecendo a determinação dos interesses do capital.

O marco teórico relevante, a partir do qual surgiu este trabalho e outros subseqüentes, é o de Frigotto (1984), o qual supera a desvinculação absoluta entre escola e produção da análise de Salm (1980), não obstante o valor do mesmo ao criticar a relação direta e mecânica entre a educação e o desenvolvimento capitalista.

Frigotto destaca a função mediadora da prática educativa escolar e sua dimensão política específica: democratizar o saber socialmente elaborado, articulando-o ao projeto hegemônico da classe trabalhadora.

É importante, neste processo de retomada teórica, evidenciar na relação trabalho e educação a evolução havida, não só considerando os dados que temos à disposição mas a forma como o $2^{2}$ grau tem sido pensado a partir dos estudos mais significativos.(5)

Nos últimos anos, especialmente em 1988 e 1989, considerando-se que o $2^{\circ}$ grau é o campo específico da discussão que está posta entre educação e trabalho, algumas publicações destacam este tema em função da elaboração da nova Lei de Diretrizes e Bases da Educação Nacional.

O tratamento da relação trabalho, educação e ensino de $2^{\circ}$ Grau se intensifica considerando que tem aumentado a demanda por esse nível de ensino por parte das classes menos favorecidas da população, as quais almejam não só a promoção no trabalho como também o acesso ao nível superior.(6)

(5) Ver em Kuenzer (1988) descrição e análise do trabalho de Lucilia Machado o qual consideramos extremamente significativo, dado o nosso objeto de análise e outros estudos. (pp. 40-96)

(6) Ver Cadernos Cedes (20) "Ensino de $2^{\circ}$ Grau: Trabalho e Educação em debate". 1988.

Paidéia, FFCLRP-USP, Rib. Preto, 6, Fevereiro/1994. 
Contraditoriamente se constata a má qualidade de ensino e a indefinição de políticas educacionais para o $2^{2}$ grau. Conseqüentemente, buscam-se alternativas levando-se em conta a ação individual dos elementos que vivem numa sociedade de classes (em que o processo de trabalho é determinado por interesses antagônicos e portanto submetidos ao capital) e que estâo condicionados pelas relações sociais concretas que se refletem na consciência humana. (Cadernos Cedes, 1988, p. 5-6)

A perspectiva pedagógica histórico-crítica evidencia a questão de que o saber produzido socialmente é força produtiva e como tal o saber é meio de produção. Entretanto, como a essência do modo de produção capitalista é a propriedade privada dos meios de produção, a tendência é tornar o saber propriedade exclusiva da classe dominante. Contraditoriamente, o saber retorado da prática dos trabalhadores é organizado, sistematizado e devolvido de forma parcelada aos mesmos, conforme os preceitos do taylorismo. Assim sendo, o trabalhador que, para produzir, necessita deter algum tipo de saber e portanto é proprietário de força produtiva, não detém os meios de produção que são de propriedade privada no capitalismo. Advém desta contradição em que os verdadeiros proprietários do saber não detém os meios de produção, a desapropriação dos trabalhadores do saber sobre o conjunto do processo.

A perspectiva da pedagogia histórico-crítica por sua vez, tendo em vista que a bandeira de luta do socialismo é a socialização dos meios de produção, considera de fundamental importância a socialização do saber elaborado.

Franco (1988), entretanto, ao afirmar que o $2^{2}$ grau padece de uma indefinição política, levanta duas questōes: uma de ordem teórica e outra de ordem prática. Quanto ao ponto de vista teórico, investe contra as interpretações assentadas na "Teoria do Capital Humano" e/ou nas "teses reprodutivistas", as quais ignoram a contradição capital-trabalho e, conseqüentemente, a relação educação-trabalho passa a ser vista numa perspectiva funcionalista. Destaca a autora como equívocos advindos destas linhas de interpretação teórica: "a simplificação do conceito de qualificação profissional; a redução da relação entre educação e trabalho para a relação entre educação e mercado de trabalho; a concepção abstrata do conceito de trabalho; o tratamento segmentado, onde escola e trabalho são vistos como realidades estanques; e finalmente, a desvalorização do saber técnico. (Franco, 1988, p. 27) 
Apesar da autora responsabilizar os autores que utilizam como suporte a Teoria Funcionalista de segmentação social(7), incorre em grande equívoco ao estabelecer uma diferenciação interna aos cursos de $2^{\mathbf{Q}}$ grau, destacando inclusive alguns que, na sua concepção, tem importância fundamental para o desenvolvimento da unidade produtiva levando em conta que o trabalhador, especialmente das pequenas e médias empresas assim como no Magistério, necessita deter o saber técnico. A autora não concorda com o "bombardeamento" à Lei 5692/71, dado que a profissionalização universal e compulsória não chegou a se implantar.

Atesta a autora que as distorções existentes são advindas da saturação do mercado posta pela existência desigual de opções profissionalizantes pois, dos cursos listados nos Anexos do Parecer 45/72 (CFE) que ultrapassam uma centena, apenas cinco Habilitações (Técnico em Secretariado, em Contabilidade, em Assistente de Administração, Magistério e Eletrônica) estão efetivamente à disposição da clientela.

Segundo Franco, "desejosa de obter uma qualificação profissional ao término do curso de $2^{\circ}$ grau". Apesar de condenar o "basismo ingênuo" e de considerar que a profissionalização "prevista" pela Lei 5692/71 foi um erro, julga indispensável "repensar a formação de técnicos a nível médio como uma alternativa possível e desejável desdé que seja uma opção mais realista para um grande contingente de trabalhadores jovens e desde que exerça uma função social enquanto elemento de desenvolvimento da cidadania" (idem, p. 31)

Desse modo propõe a manutenção e a ampliação do ensino técnico a nível de $2^{2}$ grau, deixando claro que não se opõe também ao ensino geral, desde que comprometido com a participação do cidadão em outras instâncias da sociedade civil, instrumentalizando-o de acordo com as necessidades do mundo moderno visando à transformação da sociedade brasileira.

Pelo que se depreende, a autora julga que a profissionalização, tendo como referência o modelo de ensino existente, é indispensável para um determinado tipo de aluno (os que trabalham, frequentam cursos noturnos, etc.), que almeja galgar postos mais elevados no local de trabalho mediante as

(7) Ver sobre a Teoria Estrutural-Funcionalista Machado, Lucilia R. de S. Educação e Divisão Social do Trabalho. São Paulo, 2a. ed., Cortez Ed/Aut. Assoc., 1989, pp. 91-104.

Paidéia, FFCLRP-USP, Rib. Preto, 6, Fevereiro/1994. 
credenciais educativas. De acordo com esta concepção, a ideologia subjacente ao pensamento do aluno trabalhador, ou seja, calcada na difusão da "Teoria do Capital Humano" que se tornou senso cómum, nem sequer é vislumbrada. Trata da questão educacional enquanto necessidade imediata, assim como fazem os pragmatistas.

Em outro artigo Franco (1989) analisa as possibilidades de uma proposta que possa viabilizar a organização do $2^{q}$ grau, centrada no trabalho enquanto princípio educativo, que, no seu entender, é necessária uma reestruturação curricular e uma seleção de conteúdos. Diz a autora que a relação teoria e prática enquanto forma metodológica das propostas que defendem o trabalho como princípio educativo, devem ser reexaminadas. Ao questionar a idéia proposta por Saviani (1988) no esboço elaborado para a nova L.D.B. de prover as escolas de $2^{2}$ grau "de oficinas práticas, organizadas preferencialmente como unidades socialmente produtivas, a autora comenta que "A prática não deve significar uma aplicação linear e mecânica da teoria, como se fosse possível superar, no interior da escola, a divisão ideológica entre atividade intelectual e atividade manual e como se bastasse proporcionar, aos alunos, o contato com laboratórios, oficinas, equipamentos para garantir a articulação entre ciência e processo produtivo, entre teoria e prática" (Franco, 1989, p. 36)

Manacorda adverte para o fato de que "unir ensino e trabalho e situar o processo educativo rico em conteúdos teóricos no coração da moderna produção, não é um programa pedagógico que por si se identifique o marxismo com outras pedagogias modernas (...) a prática em que pensa Marx é algo que não coincide com o objetivo individual no qual se verifica a validade de um pensamento, que é típica posiçāo do pragmatismo". (Manacorda, 1969, p. 139)

Franco, ao contrapor-se à idéia de Saviani ((1988), explicitada no Artigo 37, item III, apresentado no esboço de uma proposta de texto para a nova L.D.B., em que se contempla nos currículos das escolas de $2^{2}$ grau, além da língua nacional, a vinculação íntima do estudo teórico-prático das ciências e da matemática com o trabalho produtivo, comete no mínimo um equívoco de ordem teórico metodológica.

De toda forma a união de ensino e trabalho de que nos fala Marx não se deve confundir com as propostas das modernas escolas ativas de trabalho, mas "se trata de um trabalho produtivo, prática do manejo dos instrumentos essenciais de todos os ofícios, associado à teoria como estudo dos princípios fundamentais das ciências" (Manacorda, 1969, p. 137). 
Por outro lado, Franco apoiada em alguns princípios da Psicologia Geral embasada na perspectiva de psicólogo russo Rubinstein afirma que "o estudo em si próprio é uma atividade que, pela sua natureza muito se aproxima do trabalho (...). A atitude geral da personalidade no estudo é uma atividade de trabalho". (Franco, 1989, p. 36)

O estudo, posto desta forma, seria, assim como pensam os pragmatistas, o preparo para a atividade independente do trabalho produtivo.

Porém, a autora não se equivoca apenas uma vez. Ao apoiar-se na prática social do aluno trabalhador e considerando os antagonismos e desigualdades sociais daí decorrentes, busca justificar que nas unidades socialmente produtivas iriam-se reproduzir a fragmentação, especialização e segmentação que ocorrem no processo produtivo.

Ora, tal afirmativa desconsidera algo que Saviani nos chama a atenção, com relação ao que deverá estabelecer a L.D.B.N: "indicar os rumos implica não apenas levar em conta a situação existente mas antever para onde se quer caminhar, ou seja, delinear o tipo de sociedade que se quer construir a partir do desenvolvimento das condições presentes" (Saviani, 1988, p. 5).

A proposta de Franco com relaçẳo à organização do $2^{2}$ grau através de uma reestruturação curricular e pela seleção de conteúdos, buscando articulação do mundo do trabalho com a escola na sua "dimensão real e concreta que tem significado para o aluno" (Franco, 1989, 36), não garante as condições mínimas para que o trabalhador se liberte do processo de alienação a que está submetido.

\section{NOTAS CONCLUSIVAS}

De todo o modo a simples compreensão do conteúdo objetivo do trabalho e o desnudamento das contradições que lhes são inerentes, a transformação dos conteúdos curriculares em "conteúdos vivos", que têm ressonância na vida do estudante trabalhador, não são suficientes para 0 surgimento de uma prática revolucionária e transformadora.

É preciso que se crie o espaço necessário, "as unidades socialmente produtivas", para que se possa, com efeito, viabilizar no $2^{\mathfrak{Q}}$ grau a necessária 
explicitação direta entre educação e trabalho, recuperando assim a relação entre trabalho e conhecimento.

Se é tácito que há, na história do trabalho sob o modo de produção capitalista, um processo de alienação do trabalhador, uma crescente divisão e mecanização de tarefas e um nível de desqualificação do trabalhador que; em um determinado momento histórico, é degradante, não se cogita recuperar a relação ciência e produção por essa via.

Reiteramos que a capacitação no e para o processo de trabalho não se concretiza pela via da apropriação ativa de conteúdos voltados à compreensão de sua condição de sujeito histórico produto e produtor de realidade mas supōe o domínio do conhecimento teórico-prático das ciências e da matemática em intima vinculação com o trabalho produtivo.

O saber, enquanto domínio da ciência e dos fundamentos da técnica, converte-se em um elemento facilitador da formação de politécnicos, básica e necessária para todos, independente do tipo de ocupação que cada um venha a exercer na sociedade.

As demais propostas se aproximam desta posição seja pela ausência de referencial teórico adequado, seja pela falta de pesquisas e dados que proporcionariam uma reflexão mais sólida sobre o ensino de $2^{\circ}$ grau.

Ao retomarmos a idéia da politecnia (Kuenzer, 1988) verificamos que a escola única do trabalho no $2^{2}$ grau, aponta algumas questōes de ordem teórica e de ordem prática que devem ser enfrentadas: na construção do ensino politécnico a partir do modelo político e econômico do Brasil e nas atuais condições de desenvolvimento; na necessidade de se selecionar as áreas que podem ser consideradas efetivamente politécnicas de acordo com a sua função social; na necessidade de se elaborar as propostas curriculares com base na análise das condições objetivas de trabalho subdividido em áreas em que se possa identificar os conceitos, as tecnologias, as dimensões histórico-críticas, os códigos e as formas de participação social e política que lhe sảo próprias.

Isto porque há necessidade de superação das condições de miséria em se encontram as escolas de $2^{\mathfrak{Q}}$ grau no Brasil, já que a politecnia exige condições físicas adequadas e equipamentos onerosos.

Há a necessidade de se fazer uma revisão nos cursos de formação de professores, questionando como se pode criar condições para que se adote novos 
conteúdos e metodologias que tomem o trabalho como princípio educativo, a partir dos conceitos de totalidade, historicidade e provisoriedade da ciência.

Há necessidade de se articular o $1^{\circ}, 2^{\circ}$ e $3^{\circ}$ graus numa perspectiva de escola única, em que o ingresso no ensino superior estaria vinculado às profissões afins ao $2^{Q}$ grau cursado. Há a falta de competência do Estado em viabilizar projetos estabelecer metas, definir prioridades e recursos.

Apesar destes fatores apontados acima, que de certa forma contribuem para inviabilizar tal projeto, consideramos importante que haja um esforço no sentido de que sejam criadas condições para superação destes desafios.

Isto porque embora o trabalho como princípio educativo atenda as necessidades do capital de formar seus intelectuais, tendo em vista as exigências da modernidade, a escola politécnica é por essência a escola demandada pela classe trabalhadora, que teria, ao menos em parte, as suas necessidades de transformação da sociedade atendidas.

De qualquer forma, a polêmica sobre a viabilização de um projeto de escola para a classe trabalhadora permanece, dado que as posições, aqui delimitadas dos estudiosos, são reflexo desta situação.

Das reflexōes de Arroyo (1987), o processo de construção do educativo foi construído nos conflitos de interesse de classe para reprimir e destruir a identidade cultural e o poder da classe trabalhadora, e, quando trata da educação do trabalhador, denuncia a redução do pedagógico ao escolar, processo este que estaria desconsiderando o processo amplamente pedagógico a que está submetida a classe trabalhadora. Consideramos que o movimento social de construção - negação da educação não está fundamentalmente na escola, e que as ciências da educação só teriam avançado como teorias pedagógicas e não teriam superado as velhas concepções.

Os educadores teimam assim, em buscar o educativo "nos claustros da instituição escolar". Entram na configuração histórica deste reducionismo, as características do movimento social de hegemonia da classe burguesa, em que o campo educativo vem a ser a base da legitimação das classes socialmente improdutivas, a burguesia.

Como decorrência as classes dominantes terem tirado mais proveito da construção do educativo, surgidoa partir dos conflitos de classe, reprimindo e destruindo a identidade cultural e o poder de classe dos trabalhadores que 
poucas condições têm para compreender este processo. Esta postura secundariza a importância da prática educativa escolar na sua relação com as demais práticas sociais.

Frigotto (1984) restringe as análises que se constituem em verdadeiras armadilhas cujo resultado é o reforço do interesse da burguesia, e cujo desvio fundamental se dá na não-apreensão da especificidade política e técnica da prática educativa escolar.

O equívoco dos estudos que tratam de forma linear a correspondência entre as relaçōes sociais estabelecidas na educação e as relaçōes sociais de produção, os quais consideram que as classes subalternas estariam subjugadas a esse ordenamento, sem espaço para resistir à dominação imposta pelo capital.

Aqui delimitamos a crítica e o desafio dessa teoria, pois, à medida em que a escola e as organizaçōes de produção sāo loci de dominação, também o são de conflito e resistência à essa dominação. (8)

O resgate da escola de qualidade, disseminado nos movimentos da classe trabalhadora, torna insustentável a tese de ARROYO sobre a incapacidade dessa classe em penetrar e questionar a configuração da prática educativa escolar.

Esta impotência da classe trabalhadora diante do fato de que o saber objetivo tem sido negado historicamente ao trabalhador pela classe dominante, nãe só a nível de instituição escolar como a nível de outras instituiçōes e do próprio trabalho (em que o saber coletivo é expropriado no interior do processo produtivo), se reveste, nos movimentos de luta da classe trabalhadora, em elementos de caráter gerador das "formas de consciência" dessa classe. Daí a luta pela escolarização estar ocorrendo de forma concreta, afiançando assim a proposta de união ensino e trabalho produtivo.

Muito embora a industrialização tardia tenha esbarrado, por um lado, na miséria reinante no país, por outro lado, o avanço da ciência e da tecnologia tem trazido para o âmbito da educação escolar dificuldades jamais experimentadas.

(8) Ver MINAYO GOMES et alli. Trabalho e Conhecimento: Dilemas na Educaçăo do Trabalhador. Săo Paulo, Cortez/Aut. Assoc., 1987. 
Esta dicotomia, por assim dizer, presente no panorama político-educacional brasileiro, tem mostrado a necessidade de se intensificar as pesquisas sobre a relação trabalho-educação, no sentido de se buscar um encaminhamento que supere o atual estado de coisas.

Este é um trabalho de todos nós.

\section{ABSTRAT}

In order to understand the fundamental role and function of education in the last years of night-school, this paper intends to gine the reader a panoramic view if the progress and possible drawbooks this subyect has undergone in the academic discussions. In other words, it tries to present a synthessis of the current ideas about education in high school in the state of São Paulo, Brazil. perspectives.

Key words: teaching, teaching career, high school, theoretical

Education in high school: in search of an agreed organization with the new determinations of the work market.

\section{BIBLIOGRAFIA}

ARROYO, M. O direito do trabalhador à Educação. In MINAYO GOMES et al. Trabalho e Conhecimento: dilemas na educação do trabalhador.. São Paulo, Cortez/Autores Associados, 1987.

CADERNOS CEDES (20) O Ensino de $2^{\circ}$ Grau: Trabalho e Educação em Debate. Cortez, Ed./CEDES, 1988.

FRANCO, Maria Laura PB. (Debatedora). Pesquisa Educacional e Políticas Governamentais em Educação: Ensino de $2^{\circ}$ Grau. In CADERNOS DE PESQUISA, Fundação Carlos Chagas, São Paulo (55) nov/1985. 
FRANCO, Maria Laura P.B. O Ensino de $2^{\circ}$ Grau: Democratização? Profissionalização? Ou nem uma coisa nem outra? In EM ABERTO, Brasília, ano 3, n 19, mar/1984.

FRANCO, Maria Laura P.B. Possibilidades e Limitres no Trabalho enquanto princípio educativo. In CADERNOS DE PESQUISA (68). fev./89, pp. 29-37.

FRIGOTTO, G. A Produtividade da Escola Improdutiva: Um (re) Exame das Relações entre Educação e Estrutura Econômico-Social Capitalista. 2a. ed.., Cortez/Aut. Assoc., 1984. GRAMSCI, A. Os Intelectuais e a Organização da Cultura. Trad. de Carlos Nelson Coutinho. 2a. edição. Rio de Janeiro, Civilização Brasileira, 1978.

KUENZER, A.Z. Ensino de $2^{\circ}$ Grau: $O$ trabalho como princípio educativo. São Paulo, Cortez editora, 1988.

KUENZER, Acácia Z. Pedagogia da Fábrica: as relações de produção e a educação do trabalhador. São Paulo, Cortez/Autores Associados, 1985.

MACHADO, Lucília R.. de S. Cidadania e Trabalho no Ensino de $2^{2}$ Grau. In EM ABERTO, brasília, ano 4, $\mathrm{n}^{\mathrm{2}} 28$, out./dez. 1985. pp. 35-41. MADEIRA, Felícia R. Educação-Trabalho: um Balanço Crítico. In EM ABERTO, Brasília, ano 3, n² 19, mar./1984, pp. 1-13.

MANACORDA, Mario A. El princípio educativo en Gramsci. Salamanca, Ediciones Sigueme, 1977.

MANACORDA, Mario A. Marx y La Pedagogia Moderna. Barcelona. Oikos-Tau ed, 1969.

OLIVEIRA, Maria Beatriz L. de. Escolaridade e Processo de Trabalho: o impacto das inovaçōes tecnológicas na qualificação do trabalhador da indústria metal mecânica. São Paulo, PUC, 1991 (Tese de Doutoramento). SALM, C. Pesquisa Educacional e Políticas Governamentais em Educação: Ensino de $2^{\circ}$ Grau. In CADERNOS DE PESQUISA, São Paulo, 55: 32-34, nov./1985.

SALGADO, Maria Umbelina C. (Expositora) Pesquisa Educacional e Políticas Governamentais em Educação: Ensino de $2^{\circ}$ Grau. In CADERNOS DE PESQUISA, Fundação Carlos Chagas, São Paulo (55) nov./1985. 
SAVIANI, D. Contribuição à elaboração da nova L.D.B.: um início de conversa. In ANDE, São Paulo, 7 (13), 1988.

SAVIANI, D. Análise Crítica da Organização Escolar Brasileira através das leis 5540/68 e 5.692/71. In GARCIA, W.E. (org.) Educação Brasileira Contemporânea: Organização e Funcionamento. São Paulo, McGraw-Hill do Brasil, 1976. pp. 174-194. SAVIANI, D. Ensino Público e Algumas Falas Sobre a Universidade. Cortez/Aut. Assoc., 1986 (Coleção Polêmicas de nosso tempo, $n^{2} 10$ ).

VELLOSO, Jacques R. Socialização e Trabalho: Escola e Produção Capitalista. In EM ABERTO, Brasília, ano 3, n² 19, mar./1984, pp. 15-24.

WARDE, M.J. (Expositora) Pesquisa Educacional e Políticas Governamentais em Educação: Ensino de $2^{\circ}$ Grau. In CADERNOS DE PESQUISA, Fundação Carlos Chagas, São Paulo (55) nov./1985. 